\title{
Thirty-day readmission and reoperation rates after single-level anterior cervical discectomy and fusion versus those after cervical disc replacement
}

\author{
Niketh Bhashyam, BS, 1,2 Rafael De la Garza Ramos, MD, ,,2 Jonathan Nakhla, MD,1,2 \\ Rani Nasser, MD, ${ }^{1,2}$ Ajit Jada, MD, ${ }^{1,2}$ Taylor E. Purvis, BA, ${ }^{3}$ Daniel M. Sciubba, MD, ${ }^{3}$ \\ Merritt D. Kinon, MD,1,2 and Reza Yassari, MD, MS ${ }^{1,2}$ \\ 'Department of Neurological Surgery and ${ }^{2}$ Spine Research Laboratory, Montefiore Medical Center/Albert Einstein College \\ of Medicine, Bronx, New York; and 'Department of Neurosurgery, Johns Hopkins University School of Medicine, Baltimore, \\ Maryland
}

OBJECTIVE The goal of this study was to compare 30-day readmission and reoperation rates after single-level anterior cervical discectomy and fusion (ACDF) versus those after cervical disc replacement (CDR).

METHODS The authors used the 2013-2014 American College of Surgeons National Surgical Quality Improvement Program database. Included were adult patients who underwent first-time single-level ACDF or CDR for cervical spondylosis or disc herniation. Primary outcome measures were readmission and/or reoperation within 30 days of the original surgery. Logistic regression analysis was used to assess the independent effect of the procedure (ACDF or CDR) on outcome, and results are presented as odds ratios with 95\% confidence intervals.

RESULTS A total of 6077 patients met the inclusion criteria; 5590 (92.0\%) patients underwent single-level ACDF, and 487 (8.0\%) patients underwent CDR. The readmission rates were $2.6 \%$ for ACDF and $0.4 \%$ for CDR $(p=0.003)$. When stratified according to age groups, only patients between the ages of 41 and 60 years who underwent ACDF had a significantly higher readmission rate than those who underwent $\operatorname{CDR}(2.5 \%$ vs $0.7 \%$, respectively; $p=0.028)$. After controlling for patient age, sex, body mass index, smoking status, history of chronic obstructive pulmonary disease (COPD), diabetes, hypertension, steroid use, and American Society of Anesthesiologists (ASA) class, patients who underwent CDR were significantly less likely to undergo readmission within 30 days than patients who underwent ACDF (OR 0.23 [95\% $\mathrm{Cl} 0.06-0.95] ; p=0.041)$. Patients with a history of COPD (OR 1.97 [95\% Cl 1.08-3.57]; $p=0.026$ ) or hypertension (OR 1.62 [95\% Cl 1.10-2.38]; $p=0.013$ ) and those at ASA Class IV (OR 14.6 [95\% Cl 1.69-125.75]; $p=0.015)$ were significantly more likely to require readmission within 30 days. The reoperation rates were $1.2 \%$ for ACDF and $0.4 \%$ for CDR ( $p$ $=0.086$ ), and multivariate analysis revealed that CDR was not associated with lower odds of reoperation (OR 0.60 [95\% $\mathrm{Cl} 0.14-2.55] ; p=0.492)$. However, increasing age was associated with a higher risk (OR 1.02 [95\% $\mathrm{Cl} 1.00-1.05] ; p=$ 0.031 ) of reoperation; a $2 \%$ increase in risk per year of age was found.

CONCLUSIONS Patients who underwent single-level ACDF had a higher readmission rate than those who underwent single-level CDR in this study. When stratified according to age, this effect was seen only in the 41- to 60-year age group. No significant difference in the 30-day single-level ACDF and single-level CDR reoperation rates was found. Although patients in the ACDF group were older and sicker, other unmeasured covariates might have accounted for the increased rate of readmission in this group, and further investigation is encouraged.

https://thejns.org/doi/abs/10.3171/2016.11.FOCUS16407

KEY WORDS anterior cervical discectomy and fusion; cervical disc replacement; readmission; reoperation; NSQIP 
$\mathrm{A}$ NTERIOR cervical discectomy and fusion (ACDF) is one of the most commonly performed surgical procedures on the spine, typically used to alleviate or halt progression of myeloradiculopathy. ${ }^{5,9}$ However, ACDF inherently decreases motion between the 2 fused vertebral segments, which has led to the advent of nonfusion techniques such as cervical disc replacement (CDR). ${ }^{7,15}$ In the past decade, multiple studies have examined long-term outcomes 2, 5, and 7 years after ACDF and after CDR. ${ }^{11-14,16,17,19,20,23,31}$ These long-term analysis studies have found that CDR is generally associated with complication rates that are either similar to or lower than those with ACDF; such complications include postoperative pain, adjacent segmental degeneration, decreased segmental range of motion, and neurological degen-

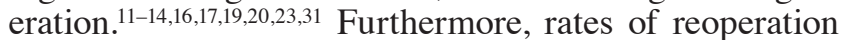
within 24-60 months have been found to be higher in patients who undergo ACDF, but according to a 7-year follow-up study by Gornet et al., ${ }^{13}$ this rate decreases as time progresses..$^{16,17,23}$

However, there are limited data on the short-term outcome of ACDF versus CDR, particularly in terms of early reoperation and readmission rates. Thus, the purpose of this study was to compare 30-day readmission and reoperation rates between patients who underwent single-level $\mathrm{ACDF}$ and those who underwent CDR.

\section{Methods \\ Study Sample}

For this study, we used the 2013-2014 American College of Surgeons National Surgical Quality Improvement Program (NSQIP) database; the study was deemed exempt from review by the local institutional review board. The NSQIP is a prospectively collected database that contains preoperative, intraoperative, and 30-day followup data on major surgical procedures from more than 300 hospitals in the United States (see https://www.facs.org/ quality-programs/acs-nsqip/about). A trained surgical clinical reviewer is responsible for data collection at each site, and patients are followed via mail, telephone calls, and medical chart reviews. ${ }^{21,29}$ According to Shiloach et al., ${ }^{29}$ the NSQIP has a $95 \%$ success rate in recording outcomes and an interrater reliability of greater than $95 \% .28$

For this study, included were patients older than 18 years who underwent single-level ACDF (Current Procedural Terminology [CPT] code 22551) or CDR (CPT code 22856). Patients who were assigned a concurrent CPT code such as 22552 were excluded to limit the selection to single-level procedures. Indications for cervical fusion such as infection, tumor, and trauma were also excluded (n = 374). Last, revision procedures and combined anterior/ posterior approaches were excluded also $(n=942)$.

\section{Collected Data}

Collected data included patient age at surgery, sex, body mass index (BMI), comorbidities, American Society of Anesthesiologists (ASA) class, operative time, and occurrence of readmission or reoperation within 30 days. Readmissions were also subclassified as related or unrelated to the primary procedure.
TABLE 1. Patient demographics

\begin{tabular}{|c|c|c|c|}
\hline \multirow[b]{2}{*}{ Parameter } & \multicolumn{2}{|c|}{ Treatment Group* } & \multirow[b]{2}{*}{ p Value } \\
\hline & $\begin{array}{c}\text { ACDF } \\
(n=5590)\end{array}$ & $\begin{array}{c}\text { CDR } \\
(n=487)\end{array}$ & \\
\hline Age (yrs) & $52 \pm 12$ & $45 \pm 10$ & $<0.001$ \\
\hline $21-40$ & 15.7 & 37.6 & \multirow{4}{*}{$<0.001$} \\
\hline $41-60$ & 60.2 & 56.5 & \\
\hline $61-75$ & 20.8 & 5.5 & \\
\hline$\geq 75$ & 3.3 & 0.4 & \\
\hline Sex & & & 0.011 \\
\hline Male & 49.6 & 55.7 & \\
\hline Female & 50.4 & 44.4 & \\
\hline BMI & $30.2 \pm 6.9$ & $28.2 \pm 5.8$ & $<0.001$ \\
\hline \multicolumn{4}{|l|}{ Comorbidities } \\
\hline Tobacco use & 29.9 & 22.0 & $<0.001$ \\
\hline COPD & 3.9 & 0.8 & $<0.001$ \\
\hline Diabetes & 14.7 & 3.5 & $<0.001$ \\
\hline Congestive heart failure & 0.2 & 0.0 & 0.350 \\
\hline Hypertension & 41.7 & 16.4 & $<0.001$ \\
\hline Steroid use & 2.8 & 1.0 & 0.019 \\
\hline Renal failure & 0.02 & 0.0 & 0.770 \\
\hline ASA class & & & $<0.001$ \\
\hline 1 & 4.3 & 16.4 & \\
\hline II & 59.0 & 67.2 & \\
\hline III & 35.3 & 16.0 & \\
\hline IV & 1.5 & 0.4 & \\
\hline Operative time (hrs) & $1.7 \pm 0.9$ & $1.8 \pm 0.8$ & 0.057 \\
\hline Length of stay (days) & $1.5 \pm 2.4$ & $1.0 \pm 0.9$ & $<0.001$ \\
\hline
\end{tabular}

\section{Statistical Analysis}

All analyses were performed in Stata SE 12 (StataCorp). Comparisons between groups were done using Student t-tests for continuous variables and the chi-square or Fisher exact test for frequencies. Multivariate logistic regression analysis was used to assess the independent effect of the procedure (ACDF or CDR) on outcome. This analysis controlled for patient age, sex, and comorbidities. Statistical significance was defined at a $p$ value of $<0.05$.

\section{Results}

\section{Demographics}

A total of 6077 patients met the inclusion criteria; 5590 (92.0\%) patients underwent single-level ACDF, and 487 patients $(8.0 \%)$ underwent CDR. Patient data were further stratified according to age, sex, comorbidities, ASA class, BMI, average operative time, and average length of stay (Table 1). Patients in the ACDF group were significantly older than patients who underwent CDR (52 vs 45 years, respectively; $p<0.001)$. The highest percentages of patients who underwent ACDF or CDR were between the ages of 41 and 60 years (60.2\% vs $56.5 \%$, respectively) and were categorized at ASA Class II (59.0\% vs 67.2\%, 

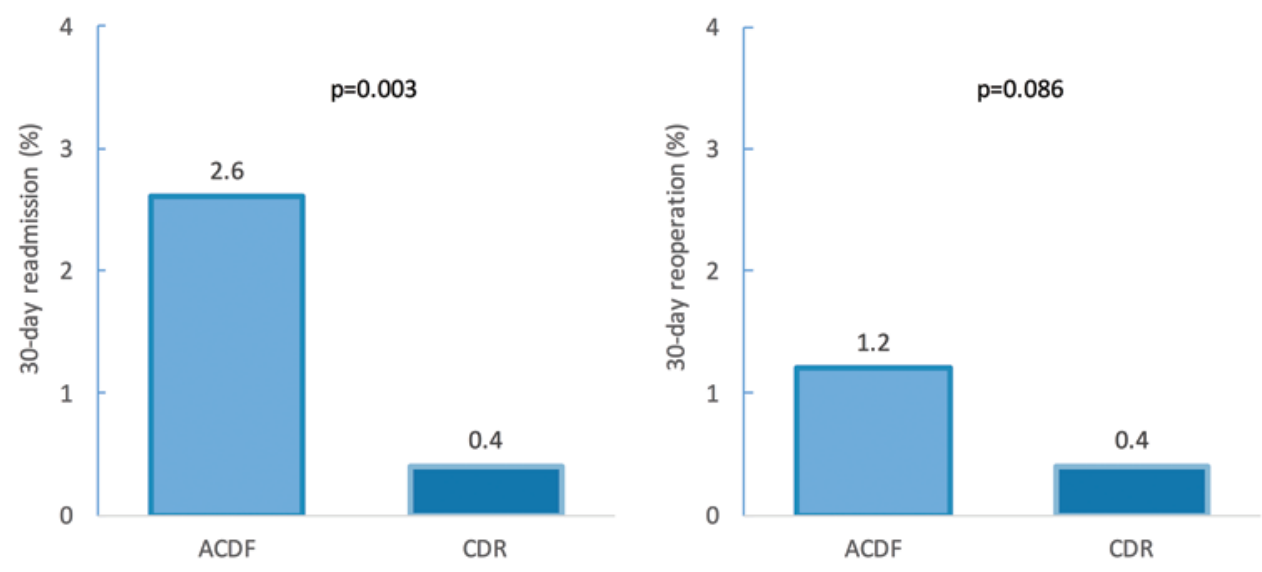

FIG. 1. Thirty-day readmission (left) and reoperation (right) rates for ACDF and CDR.

respectively). Males were found to undergo CDR more often (55.7\%) than ACDF (49.6\%), and females were found to undergo ACDF more often (50.4\%) than CDR (44.4\%) $(\mathrm{p}=0.011)$. The percentages of patients with a comorbidity such as tobacco use (29.9\% vs $22.0 \%$, respectively; $p$ $<0.001$ ), chronic obstructive pulmonary disease (COPD) (3.9\% vs $0.8 \%$, respectively; $\mathrm{p}<0.001)$, diabetes $(14.7 \%$ vs $3.5 \%$, respectively; $\mathrm{p}<0.001)$, hypertension $(41.7 \%$ vs $16.4 \%$, respectively; $\mathrm{p}<0.001)$, or steroid use $(2.8 \%$ vs $1.0 \%$, respectively; $\mathrm{p}=0.019$ ) were significantly higher in the ACDF group than in the CDR group.

\section{0-Day Readmission Rates}

Patients who underwent ACDF were more likely to be readmitted within 30 days than were patients who underwent CDR (2.6\% vs $0.4 \%$, respectively; $p=0.003$ ) (Fig. 1). When stratified according to age groups, patients between the ages of 41 and 60 years were also found to undergo readmission after ACDF significantly more often than after CDR (2.6\% vs $0.7 \%$, respectively; $p=0.028$ ) (Fig. 2 ). Causes of readmission and the numbers of patients readmitted are reported in Table 2. The most common unique causes for readmission in the ACDF group were pneumonia, hematoma, and dysphagia; in the CDR group, 1 case of surgical site infection (SSI) and 1 case of neck swelling occurred.

\section{0-Day Reoperation Rates}

No significant difference in the rates of reoperation between patients who underwent $\mathrm{ACDF}$ and those who underwent CDR $(1.2 \%$ and $0.4 \%$, respectively; $\mathrm{p}=0.086)$ was found (Fig. 1). Causes of the reoperations are listed in Table 3. Reoperation rates after ACDF and CDR stratified according to age group were $0.2 \%$ and $0.6 \%$ for patients aged $21-40$ years $(\mathrm{p}=0.434), 1.0 \%$ and $0.4 \%$ for patients aged $41-60$ years $(\mathrm{p}=0.231), 2.0 \%$ and $0.0 \%$ for patients aged $61-75$ years $(\mathrm{p}=0.587)$, and $2.7 \%$ and $0.0 \%$ for patients older than 75 years $(p=0.947)$, respectively.

\section{Multivariate Analysis}

After controlling for patient age, sex, BMI, smoking status, history of COPD, diabetes, hypertension, steroid use, and ASA class, patients who underwent CDR were significantly less likely to experience a 30-day readmission compared with patients who underwent ACDF (OR 0.23 [95\% CI 0.06-0.94]; $\mathrm{p}=0.041$ ). Patients with a history of COPD (OR 1.97 [95\% CI 1.08-3.57]; $\mathrm{p}=0.026$ ) or hypertension (OR 1.62 [95\% CI 1.10-2.38]; $\mathrm{p}=0.013$ ) and those at ASA Class IV (OR 14.6 [95\% CI 1.69-125.75]; $\mathrm{p}=0.015$ ) were significantly more likely to experience a readmission within 30 days.

Multivariate analysis revealed that CDR was not associated with lower odds of reoperation (OR 0.60 [95\% CI $0.14-2.56] ; \mathrm{p}=0.492)$. Increasing age (OR 1.02 [95\% CI $1.00-1.05] ; \mathrm{p}=0.031$ ) was associated with a higher risk of reoperation; we found a $2 \%$ increase in risk per year of age.

\section{Discussion}

$\mathrm{ACDF}$ and CDR are 2 methods of treating symptomatic cervical spondylosis or disc herniation after failure of nonoperative treatment or when there is progressive neurological deficit. ACDF is currently performed much more commonly than CDR, because it has become the gold standard of treatment. ${ }^{1,3,5,6,10,24}$ In the past decade, a growing interest in CDR as an alternative to ACDF in multiple long-term studies has revealed outcomes that are similar to or slightly better than those for ACDF.11-14,16,17,19, 20,23,25,31 However, there are limited data regarding 30-day readmission and reoperation rates among those who have undergone 1 of these 2 procedures; the main objective of this investigation was to obtain such data. In this study, we found that patients who underwent $\mathrm{ACDF}$ were more likely to be readmitted within 30 days than were patients who underwent CDR. When stratified according to age, only patients between the ages of 41 and 60 years were found to be readmitted significantly more for complications related to ACDF than for those related to CDR. We also found no significant difference in the reoperation rates between patients who underwent $\mathrm{ACDF}$ and those who underwent CDR.

The results of this study add a novel perspective to the results of various comparative studies between ACDF and CDR regarding 30-day outcomes. Our study revealed a 
A

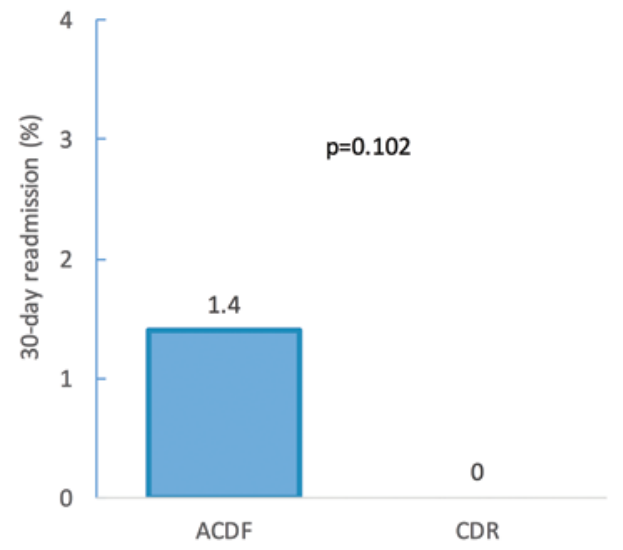

$\mathrm{C}$

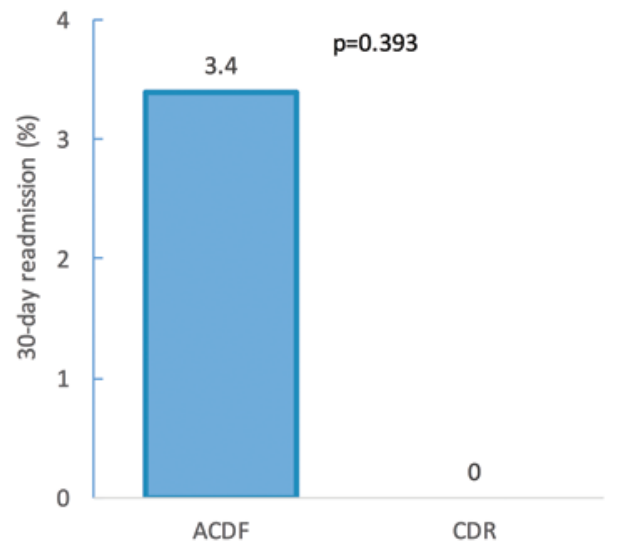

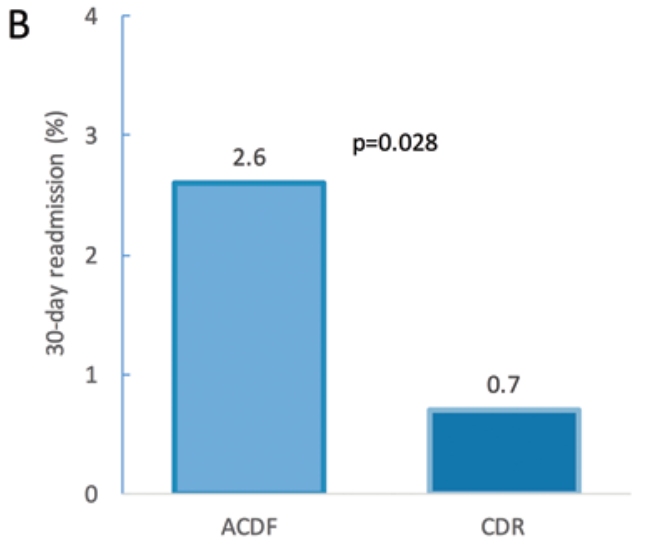

D

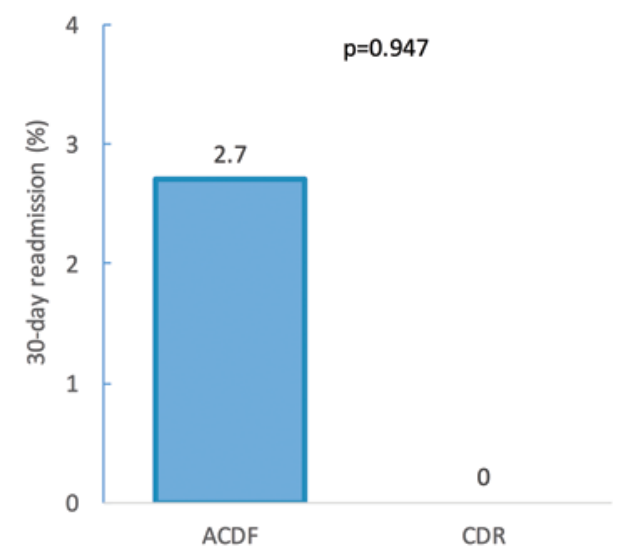

FIG. 2. Thirty-day readmission rates stratified according to age: $21-40$ years (A), 41-60 years (B), $61-75$ years (C), and $\geq 75$ years (D).

higher 30-day readmission rate after ACDF, especially in 41- to 60-year-old patients. Furthermore, we found no difference between CDR and ACDF 30-day reoperation rates, similar to 2 previously published studies by Heller et al. ${ }^{14}$ and Murrey et al. ${ }^{23}$ these 2 studies found no differences in reoperation rates at 12 and 24 months or at 6 weeks and 3, 6, 9, 12, and 18 months, respectively. In addition, Murrey et al. found that reoperation rates after ACDF were higher than those after CDR at 24 months. Therefore, our results support the notion that longer postoperation time is necessary to find significant differences between related reoperation rates after ACDF and those after CDR. The time period necessary to find significant differences between these reoperation rates might be at least 24 months. ${ }^{26}$

Our study found that the most common causes of readmission related to the index ACDF or CDR procedure are classified under the "other" category (Table 2). This category encompasses any complications that are related to the index surgery but are neither related to the surgical site nor specified in the NSQIP database as variables. Similarly, from their study, Samuel et al. ${ }^{26}$ concluded that the most common cause of readmission after ACDF was non-surgical site-related issues. Furthermore, Samuel et al. ${ }^{26}$ and Ban et al. ${ }^{2}$ stated that pneumonia, dysphagia, and hemorrhage/hematoma are prominent causes of readmis- sion after ACDF, which correlates to the results of our study; we found these conditions to be the next-largest causes of readmission after single-level ACDF (Table 2). Organ-space SSI and a swelling, mass, or lump in the neck were found in equal numbers to be the cause of readmission after single-level CDR (Table 2). This result is in contrast to the findings of De la Garza-Ramos et al., ${ }^{8}$ who found no cases of SSI after CDR between the years 2006 and 2012. Overall, few data regarding causes of readmission that result from CDR exist.

There were multiple different causes of readmission in the ACDF group, including pneumonia, SSI, hematoma, dysphagia, vocal cord paralysis, and esophageal perforation, among others. The fact that these events were not found in the CDR group was interesting and also surprising; it might be a result of the lower number of observations in the CDR group, but it also might be related to the fact that patients in the ACDF group were, on average, older and sicker. Although we attempted to control for these factors with multivariate analysis, other unmeasured covariates, such as cervical spine alignment/deformity, degree of stenosis, presence or absence of ossified ligament, and others, might have contributed to the increased risk of readmission, including higher rates of admission for dysphagia and hematoma. However, patients with a history of COPD or hypertension and those at ASA Class IV were at 
TABLE 2. Causes of readmission

\begin{tabular}{lcc}
\hline & \multicolumn{2}{c}{ Treatment Group } \\
\cline { 2 - 3 } Readmission Cause & ACDF $(\mathrm{n}=145)$ & $\mathrm{CDR}(\mathrm{n}=2)$ \\
\hline Related & 106 & 2 \\
\hline Cerebrovascular accident & 1 & 0 \\
\hline Deep incisional SSI & 3 & 0 \\
\hline Organ space SSI & 3 & 1 \\
\hline Unspecified SSI & 2 & 0 \\
\hline Pneumonia & 10 & 0 \\
\hline Pulmonary embolism & 3 & 0 \\
\hline Sepsis & 2 & 0 \\
\hline Superficial SSI & 4 & 0 \\
\hline Unplanned intubation & 1 & 0 \\
\hline Urinary tract infection & 1 & 0 \\
\hline Deep venous thrombosis & 1 & 0 \\
\hline Wound disruption & 1 & 0 \\
\hline Dysphagia & 7 & 0 \\
\hline Epidural hematoma & 8 & 0 \\
\hline Swelling/mass/lump in neck & 3 & 1 \\
\hline Other/unknown & 56 & 1 \\
\hline Unrelated & 39 & 0 \\
\hline
\end{tabular}

Values represent the number of patients.

higher risk of readmission, which supports the hypothesis of a sicker population and has also been found in previous investigations. ${ }^{18,30}$ Future research specifically into shortterm outcomes of ACDF and CDR might further corroborate or challenge these findings.

Another potential causative factor for our findings could relate to the differences in operative techniques for the ACDFs and CDRs. Although the surgical approach is generally the same (traditional Smith-Robinson approach), and hence unlikely to be responsible for the observed differences, 2 specific differing operative steps might play prominent roles. First, the placement of the graft in CDR requires fine endplate preparation (to ensure proper alignment of the prosthesis) and appropriate device sizing. This step is not fundamentally different in the two surgeries, but for CDR, the neck position is usually neutral, whereas for ACDF, more extension can be tolerated and is used routinely to improve access. ${ }^{22} \mathrm{We}$ have noticed that a number of patients who undergo extension during ACDF complain of postoperative muscle spasms that generally subside within 6-8 weeks. Second, the instrumentation techniques used in ACDF need to be considered; the use of plates in ACDF has been linked to the development of dysphagia, ${ }^{27}$ which was the cause of readmission for several patients who underwent this procedure in our study. Furthermore, it has been hypothesized that the decrease in motion caused by ACDF can lead to the formation of more scar tissue than that caused by CDR and also can potentially contribute to swallowing difficulty. ${ }^{27}$ In line with this hypothesis, it has been suggested that dysphagia increases the risk of aspiration and pneumonia. ${ }^{4}$ Nonetheless, the higher morbidity rate after ACDF is most likely multifactorial and cannot be
TABLE 3. Causes of reoperation

\begin{tabular}{|c|c|c|}
\hline \multirow[b]{2}{*}{ Reoperation Cause } & \multicolumn{2}{|c|}{ Treatment Group } \\
\hline & $\begin{array}{c}\text { ACDF } \\
(n=65)\end{array}$ & $\begin{array}{c}\text { CDR } \\
(n=2)\end{array}$ \\
\hline Intraspinal abscess & 1 & 0 \\
\hline Unspecified disease of spinal cord & 1 & 0 \\
\hline Unilat paralysis of vocal cord & 1 & 0 \\
\hline Edema of larynx & 1 & 0 \\
\hline Perforation of esophagus & 1 & 0 \\
\hline Cellulitis \& abscess of neck & 1 & 0 \\
\hline Spondylosis \& allied disorders & 2 & 0 \\
\hline Cervical spondylosis w/ myelopathy & 1 & 0 \\
\hline Intervertebral disc disorder & 1 & 1 \\
\hline Other disorders of cervical region & 5 & 0 \\
\hline Residual foreign body in soft tissue & 1 & 0 \\
\hline Other \& unspecified disorder of bone \& cartilage & 1 & 0 \\
\hline Dysphagia & 1 & 0 \\
\hline Spinal cord injury & 1 & 0 \\
\hline Implant-related complication & 4 & 0 \\
\hline Hemorrhage/hematoma complicating a procedure & 13 & 0 \\
\hline Seroma complicating a procedure & 1 & 0 \\
\hline SSI & 5 & 0 \\
\hline Retained foreign body & 1 & 0 \\
\hline Other/unknown & 22 & 1 \\
\hline
\end{tabular}

Values represent the number of patients.

attributable to the subtle differences in the respective procedures alone.

One of the limitations of this study is that it provides Level 3 evidence. Therefore, the retrospective and nonblinded nature of this evidence can lead to recall or selection biases, which can skew the collected data. Furthermore, because data identification and acquisition in the NSQIP are done through codes, there is a risk of coding or information bias, regardless of the quality-control measures that the NSQIP tries to maintain. Last, the NSQIP is a database that is not specific for patients undergoing spine surgery, which limited our ability to procure any in-depth information about the specific patients and procedures we were studying. Nevertheless, the NSQIP is a widely used database with high accuracy and reproducibility. ${ }^{28}$

\section{Conclusions}

ACDF is a procedure performed more commonly than CDR in patients with symptomatic cervical spondylosis. Although no significant difference in 30-day reoperation rates was found, patients who underwent single-level $\mathrm{ACDF}$ were found, in general, to be older, sicker, and readmitted significantly more often for related complications than the patients who underwent single-level CDR. Furthermore, only patients between the ages of 41 and 60 years were found to have a rate of readmission attributable to related complications from single-level ACDF that was significantly higher than that for single-level CDR. 


\section{Acknowledgments}

The American College of Surgeons NSQIP and its participating hospitals were the source of the data used herein; they have not verified and are not responsible for the statistical validity of the data analysis or the conclusions derived by the authors.

\section{References}

1. Bailey RW, Badgley CE: Stabilization of the cervical spine by anterior fusion. J Bone Joint Surg Am 42-A:565-594, 1960

2. Ban D, Liu Y, Cao T, Feng S: Safety of outpatient anterior cervical discectomy and fusion: a systematic review and meta-analysis. Eur J Med Res 21:34, 2016

3. Bartolozzi P, Salvi M: Anterior surgery of the lower cervical spine. Chir Organi Mov 77:81-85, 1992

4. Bohl DD, Ahn J, Rossi VJ, Tabaraee E, Grauer JN, Singh K: Incidence and risk factors for pneumonia following anterior cervical decompression and fusion procedures: an ACSNSQIP study. Spine J 16:335-342, 2016

5. Bohlman HH, Emery SE, Goodfellow DB, Jones PK: Robinson anterior cervical discectomy and arthrodesis for cervical radiculopathy. Long-term follow-up of one hundred and twenty-two patients. J Bone Joint Surg Am 75:1298-1307, 1993

6. Clements DH, O'Leary PF: Anterior cervical discectomy and fusion. Spine (Phila Pa 1976) 15:1023-1025, 1990

7. Coric D, Nunley PD, Guyer RD, Musante D, Carmody CN, Gordon CR, et al: Prospective, randomized, multicenter study of cervical arthroplasty: 269 patients from the KineflexIC artificial disc investigational device exemption study with a minimum 2-year follow-up: clinical article. J Neurosurg Spine 15:348-358, 2011

8. De la Garza-Ramos R, Abt NB, Kerezoudis P, McCutcheon BA, Bydon A, Gokaslan Z, et al: Deep-wound and organspace infection after surgery for degenerative spine disease: an analysis from 2006 to 2012. Neurol Res 38:117-123, 2016

9. Faldini C, Leonetti D, Nanni M, Di Martino A, Denaro L, Denaro V, et al: Cervical disc herniation and cervical spondylosis surgically treated by Cloward procedure: a 10-yearminimum follow-up study. J Orthop Traumatol 11:99-103, 2010

10. Farrokhi MR, Ghaffarpasand F, Khani M, Gholami M: An evidence-based stepwise surgical approach to cervical spondylotic myelopathy: a narrative review of the current literature. World Neurosurg 94:97-110, 2016

11. Garrido BJ, Taha TA, Sasso RC: Clinical outcomes of Bryan cervical disc arthroplasty a prospective, randomized, controlled, single site trial with 48-month follow-up. J Spinal Disord Tech 23:367-371, 2010

12. Goffin J, van Loon J, Van Calenbergh F, Lipscomb B: A clinical analysis of 4- and 6-year follow-up results after cervical disc replacement surgery using the Bryan Cervical Disc Prosthesis. J Neurosurg Spine 12:261-269, 2010

13. Gornet MF, Burkus JK, Shaffrey ME, Nian H, Harrell FE Jr: Cervical disc arthroplasty with Prestige LP disc versus anterior cervical discectomy and fusion: seven-year outcomes. Int J Spine Surg 10:24, 2016

14. Heller JG, Sasso RC, Papadopoulos SM, Anderson PA, Fessler RG, Hacker RJ, et al: Comparison of BRYAN cervical disc arthroplasty with anterior cervical decompression and fusion: clinical and radiographic results of a randomized, controlled, clinical trial. Spine (Phila Pa 1976) 34:101-107, 2009

15. Hilibrand AS, Carlson GD, Palumbo MA, Jones PK, Bohlman HH: Radiculopathy and myelopathy at segments adjacent to the site of a previous anterior cervical arthrodesis. J Bone Joint Surg Am 81:519-528, 1999

16. Hisey MS, Bae HW, Davis RJ, Gaede S, Hoffman G, Kim
KD, et al: Prospective, randomized comparison of cervical total disk replacement versus anterior cervical fusion: results at 48 months follow-up. J Spinal Disord Tech 28:E237E243, 2015

17. Hisey MS, Zigler JE, Jackson R, Nunley PD, Bae HW, Kim $\mathrm{KD}$, et al: Prospective, randomized comparison of one-level Mobi-C cervical total disc replacement vs. anterior cervical discectomy and fusion: results at 5-year follow-up. Int $\mathbf{J}$ Spine Surg 10:10, 2016

18. Karhade AV, Vasudeva VS, Dasenbrock HH, Lu Y, Gormley WB, Groff MW, et al: Thirty-day readmission and reoperation after surgery for spinal tumors: a National Surgical Quality Improvement Program analysis. Neurosurg Focus 41(2):E5, 2016

19. Lee JH, Kim JS, Lee JH, Chung ER, Shim CS, Lee SH: Comparison of cervical kinematics between patients with cervical artificial disc replacement and anterior cervical discectomy and fusion for cervical disc herniation. Spine J 14:1199-1204, 2014

20. Li Z, Yu S, Zhao Y, Hou S, Fu Q, Li F, et al: Clinical and radiologic comparison of dynamic cervical implant arthroplasty versus anterior cervical discectomy and fusion for the treatment of cervical degenerative disc disease. J Clin Neurosci 21:942-948, 2014

21. Lieber BA, Appelboom G, Taylor BE, Lowy FD, Bruce EM, Sonabend AM, et al: Preoperative chemotherapy and corticosteroids: independent predictors of cranial surgical-site infections. J Neurosurg 125:187-195, 2016

22. McAfee PC: Complications of anterior cervical approaches: cervical revision: approach-related considerations, in Yue JJ, Bertagnoli R, McAfee PC, An HS (eds): Motion Preservation Surgery of the Spine: Advanced Techniques and Controversies. Philadelphia: Saunders Elsevier, 2008, Vol 1, pp 277-286

23. Murrey D, Janssen M, Delamarter R, Goldstein J, Zigler J, Tay B, et al: Results of the prospective, randomized, controlled multicenter Food and Drug Administration investigational device exemption study of the ProDisc-C total disc replacement versus anterior discectomy and fusion for the treatment of 1-level symptomatic cervical disc disease. Spine J 9:275-286, 2009

24. Palit M, Schofferman J, Goldthwaite N, Reynolds J, Kerner M, Keaney D, et al: Anterior discectomy and fusion for the management of neck pain. Spine (Phila Pa 1976) 24:22242228, 1999

25. Qureshi SA, McAnany S, Goz V, Koehler SM, Hecht AC: Cost-effectiveness analysis: comparing single-level cervical disc replacement and single-level anterior cervical discectomy and fusion: clinical article. J Neurosurg Spine 19:546554, 2013

26. Samuel AM, Fu MC, Toy JO, Lukasiewicz AM, Webb ML, Bohl DD, et al: Most 30-day Readmissions after anterior cervical discectomy and fusion are not due to surgical siterelated issues: an analysis of 17,088 patients. Spine (Phila Pa 1976) 41:1801-1807, 2016

27. Segebarth B, Datta JC, Darden B, Janssen ME, Murrey DB, Rhyne A, et al: Incidence of dysphagia comparing cervical arthroplasty and ACDF. SAS J 4:3-8, 2010

28. Sellers MM, Merkow RP, Halverson A, Hinami K, Kelz RR, Bentrem DJ, et al: Validation of new readmission data in the American College of Surgeons National Surgical Quality Improvement Program. J Am Coll Surg 216:420-427, 2013

29. Shiloach M, Frencher SK Jr, Steeger JE, Rowell KS, Bartzokis $\mathrm{K}$, Tomeh MG, et al: Toward robust information: data quality and inter-rater reliability in the American College of Surgeons National Surgical Quality Improvement Program. J Am Coll Surg 210:6-16, 2010

30. Su AW, Habermann EB, Thomsen KM, Milbrandt TA, Nassr A, Larson AN: Risk factors for 30-day unplanned readmis- 
sion and major perioperative complications after spine fusion surgery in adults: a review of the National Surgical Quality Improvement Program database. Spine (Phila Pa 1976) 41:1523-1534, 2016

31. Tracey RW, Kang DG, Cody JP, Wagner SC, Rosner MK, Lehman RA Jr: Outcomes of single-level cervical disc arthroplasty versus anterior cervical discectomy and fusion. J Clin Neurosci 21:1905-1908, 2014

\section{Disclosures}

Dr. Sciubba has consulting relationships with Medtronic, Globus, Orthofix, Stryker, and DePuy Synthes.

\section{Author Contributions}

Conception and design: Yassari, Bhashyam, De la Garza Ramos, Nakhla, Sciubba. Acquisition of data: De la Garza Ramos, Nakhla, Purvis. Analysis and interpretation of data: all authors. Drafting the article: all authors. Critically revising the article: Yassari, De la Garza Ramos, Nasser, Jada, Sciubba, Kinon. Reviewed submitted version of manuscript: Yassari, Nasser, Jada, Sciubba, Kinon. Approved the final version of the manuscript on behalf of all authors: Yassari. Statistical analysis: Bhashyam, De la Garza Ramos, Nakhla, Purvis. Study supervision: Yassari, Sciubba, Kinon.

\section{Correspondence}

Reza Yassari, Department of Neurological Surgery, Montefiore Medical Center/Albert Einstein College of Medicine, 3316 Rochambeau Ave., Bronx, NY 10467. email: ryassari@ montefiore.org. 